\title{
ASPECTOS FITOGEOGRÁFICOS DA BACIA HIDROGRÁFICA DO ARROIO LAJEADO GRANDE, RS - BRASIL. 3 - VEGETAÇÃO DE CORNIJAS E MORROTES DE ARENITO ${ }^{1}$
}

\author{
FABIANO DA SILVA ALVES ${ }^{2}$ JOSÉ NEWTON CARDOSO MARCHIORI ${ }^{3}$ \\ LUIS EDUARDO DE SOUZA ROBAINA ${ }^{4}$
}

\begin{abstract}
RESUMO
Na bacia do arroio Lajeado Grande, oeste do Rio Grande do Sul, foram reconhecidas distintas tipologias de vegetação natural, intimamente relacionadas ao meio físico. No presente trabalho é caracterizada a vegetação das cornijas e dos morrotes de arenito. Estas duas tipologias, embora ocupando áreas pequenas, constituem importantes ecossistemas na região. Como áreas de refúgio para a vegetação silvática, abrigam grande diversidade vegetal, bem como espécies raras ou endêmicas do oeste sul-rio-grandense. A localização e distribuição geográfica destas tipologias são apresentadas em mapa fitogeográfico.

Palavras-chave: Fitogeografia, Rio Grande do Sul, arroio Lajeado Grande, vegetação das cornijas de arenito, vegetação dos morrotes de arenito.
\end{abstract}

\section{ABSTRACT}

[Phytogeographic features in the basin of Lajeado Grande stream, Rio Grande do Sul state Brazil. 3 - The vegetation of rocky slope steps and sandstone slope hills].

Different types of natural vegetation closely related to physical environment were recognized in the basin of Lajeado Grande stream, west region of Rio Grande do Sul state, Brazil. The vegetation of rocky slope steps and sandstone slope hills are presently characterized. These two types, though occupying small areas, are important ecosystems in the region, as refuge areas for the wild vegetation, home to great plant diversity and rare or endemic species in the west of Rio Grande do Sul state. The localization and geographic distribution of these types are presented in a phytogeographical map.

Keywords: Phytogeography, Rio Grande do Sul state (Brazil), Lajeado Grande stream, vegetation of rocky slope steps, vegetation of sandstone slope hills.

\section{INTRODUÇÃO}

O oeste do Rio Grande do Sul carece de estudos detalhados sobre a composição florística, distribuição geográfica e vinculações da vege-

\footnotetext{
Extraído de "Estudos fitogeográficos na bacia hidrográfica do arroio Lajeado Grande - oeste do RS", Dissertação de Mestrado defendida pelo primeiro autor em dezembro de 2008, no Programa de Pós-Graduação em Geografia - UFSM. Apoio: FAPERGS - Procorede III -0614357.

2 Prof., MSc., Universidade da Região da Campanha URCAMP.

3 Prof., Dr., Programa de Pós-Graduação em Engenharia Florestal - UFSM e Bolsista de Produtividade em Pesquisa (CNPq - Brasil).

4 Prof., Dr., Programa de Pós-Graduação em Geografia UFSM.
}

tação natural com o meio físico. Frente esta situação - e com o interesse de contribuir para o avanço do conhecimento científico, bem como alertar sobre a necessidade de conservação e preservação da biodiversidade e das paisagens naturais no Estado -, o presente trabalho tem o objetivo de identificar, caracterizar e mapear diferentes tipologias de vegetação campestre na bacia hidrográfica do arroio Lajeado Grande, com base em aspectos fisionômicos, florísticos e fitoecológicos.

Localizada no oeste do Rio Grande do Sul, em área dos municípios de Alegrete e Manoel Viana, mais precisamente entre as coordenadas geográficas de $55^{\circ} 20^{\prime} 28^{\prime \prime}$ e $55^{\circ} 36^{\prime} 42^{\prime \prime}$ de longitude oeste, e $29^{\circ} 36^{\prime} 20^{\prime \prime}$ e $29^{\circ} 59^{\prime}$ '52" de lati- 


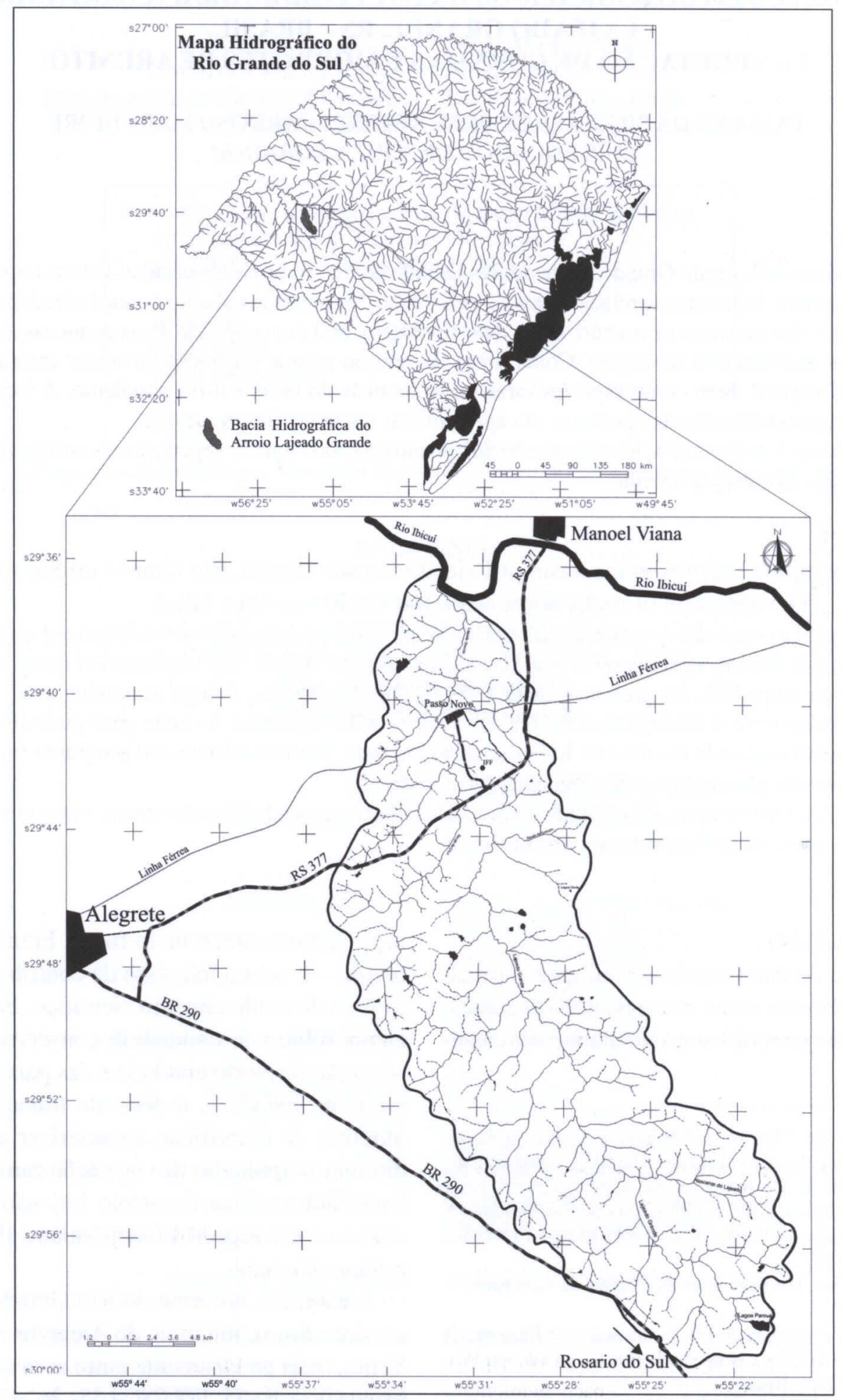

FIGURA 1 - Mapa de localização da bacia hidrográfica do arroio Lajeado Grande. 
tude sul, a bacia do arroio Lajeado Grande (Figura 1) compreende diversas tipologias de vegetação natural. No presente trabalho é caracterizada a vegetação das cornijas e dos morrotes de arenito.

\section{MATERIAIS E MÉTODOS}

Com base no mapa morfolitológico da bacia do arroio Lajeado Grande, apresentado em artigo anterior ${ }^{5}$, em imagens de satélite (ETM Landsat e Google Earth) e em observações in $l o c o$, o estudo da vegetação visou definir e mapear, inicialmente, as áreas de ocorrência das distintas tipologias, com base em aspectos fisionômicos.

Na sequência, foram realizados levantamentos florísticos detalhados em áreas com baixos índices de alteração antrópica. Nesta etapa, utilizou-se uma ficha de inventário fitogeográfico baseada no modelo proposto por Bertrand (1966), constante em Passos (2003). Além de informações gerais (local, data e pesquisadores), foram anotados aspectos relativos à fisionomia da vegetação na área amostral (campestre e/ou arbóreo-arbustiva), a localização geográfica (coordenadas), a identificação botânica das espécies, além de aspectos do meio físico (recursos hídricos, relevo, solos, etc.). A identificação das espécies vegetais, realizada inicialmente a campo, teve a amostragem encerrada, em cada tipologia, com base na curva do coletor. Para espécies não identificadas no campo, coletouse material vegetativo e/ou reprodutivo, visando posterior análise em laboratório, com o auxílio de bibliografia especializada e chaves de identificação.

O levantamento de informações do meio físico possibilitou a realização de uma análise fitoecológica, permitindo que as tipologias, definidas inicialmente sob os pontos de vista

5 ALVES, F. da S.; ROBAINA, L.E. de S.; MARCHIORI, J.N.C. Aspectos fitogeográficos da bacia hidrográfica do arroio Lajeado Grande, RS - Brasil. 1 - O meio físico. Balduinia, Santa Maria, n. 18, p. 1 - 9, 2009. fisionômico e florístico, fossem também caracterizadas com base nos habitats de ocorrência, bem como georreferenciadas e sobrepostas ao mapa morfolitológico. A sobreposição cartográfica destas informações levou ao reconhecimento e caracterização precisa das tipologias, bem como de seus respectivos habitats preferenciais.

A caracterização e mapeamento destas unidades, somadas à base cartográfica do mapa morfolitológico, possibilitou, com a utilização dos softwares GTM PRO versão 4.6 (SIG) e Corel Draw X3 (edição gráfica), a elaboração do mapa fitogeográfico, que inclui as áreas de ocorrência das diferentes tipologias naturais de vegetação, objeto do presente trabalho.

\section{DESCRIÇÃO DAS TIPOLOGIAS}

Apesar das marcas evidentes de ação antrópica em grande parte da bacia, o reconhecimento de tipologias de vegetação tornou-se possível graças à análise integrada de aspectos fisionômicos, florísticos e fitoecológicos. A distribuição geográfica da vegetação de cornijas e morrotes de arenito é apresentada na Figura 2, e caracterizadas a seguir:

\section{1 - Vegetação de Cornijas}

Formadas por afloramentos de rocha arenítica à meia encosta de colinas, as cornijas apresentam vegetação singular, baseada em microfanerófitas xerófilas e plantas suculentas, compondo uma associação arbustivo-arbórea. Nestes degraus rochosos, destaca-se a criúva (Agarista eucalyptoides (Cham. \& Schlecht.) G. Don) como espécie mais característica, seguindo-se o jasmim-catavento (Tabernaemontana catharinensis DC.), o curupi (Sapium haematospermum Müll. Arg.) e a tuna (Cereus hildmannianus K. Schum.), entre outras (Figuras $3 \mathrm{e} 4$ ).

Em alguns locais encontram-se, ainda: o tarumã-preto (Vitex megapotamica (Spreng.) Moldenke), o chá-de-bugre (Casearia sylvestris Sw.), a figueira-do-mato (Ficus luschnathiana 


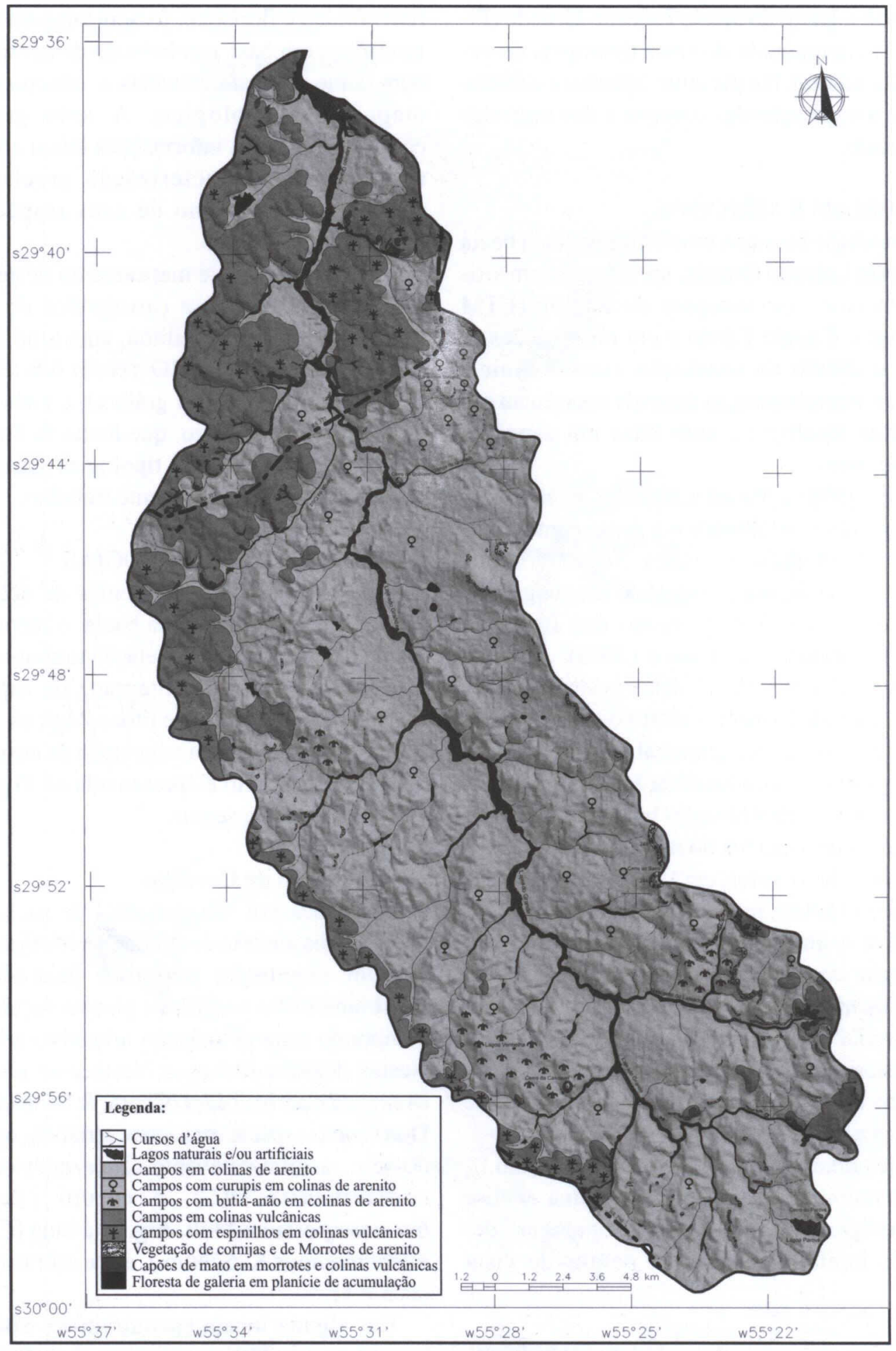

FIGURA 2 - Mapa fitogeográfico da bacia do arroio Lajeado Grande. 


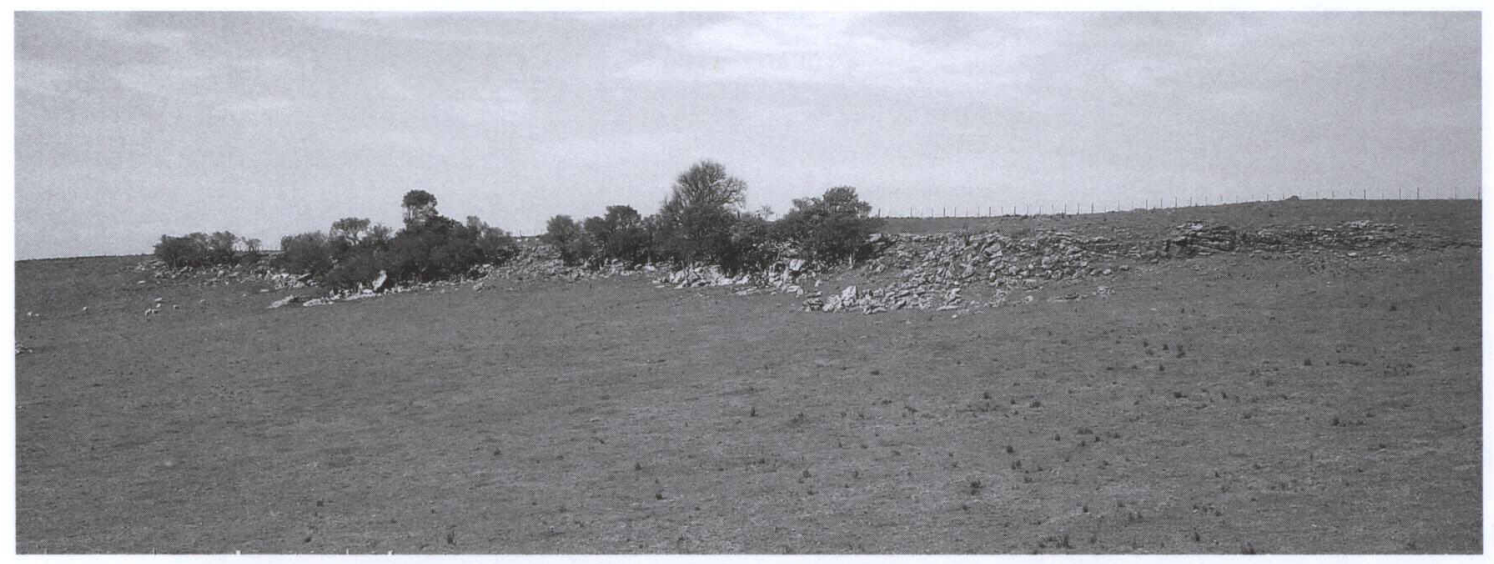

FIGURA 3 - Cornija de arenito, com vegetação característica.

(Miq.) Miq.), a japecanga (Smilax campestris Griseb.), a pixirica (Miconia hyemalis A. St.Hil. \& Naudin), a aroeira-brava (Lithraea molleoides (Vell.) Engl.), o molho (Schinus polygamus (Cav.) Cabrera), o coentrilho (Zanthoxylum fagara (L.) Sarg.), a mamica-decadela (Zanthoxylum rhoifolium Lam.), o camboatá-vermelho (Cupania vernalis Cambess.), o camboatá-branco (Matayba elaeagnoides Radlk.), o cocão (Erythroxylum microphylum A.St.-Hil.), o fumo-bravo
(Solanum mauritianum Scop.), o aguaí-vermelho (Chrysophyllum marginatum (Hook. \& Arn.) Radlk.), o guamirim (Myrceugenia glaucescens (Cambess.) D. Legrand \& Kausel), a canela-preta (Nectandra megapotamica (Spreng.) Mez), a capororoca (Myrsine laetevirens (Mez) Arechav.), e a cancorosa (Maytenus muelleri Schwacke). Das suculentas, destacam-se: a arumbeva (Opuntia arechavaletai Speg.), a tunabola (Echinocactus muricatus K. Schum.) e o cravo-das-pedras (Tillandsia lorentziana Gris.).

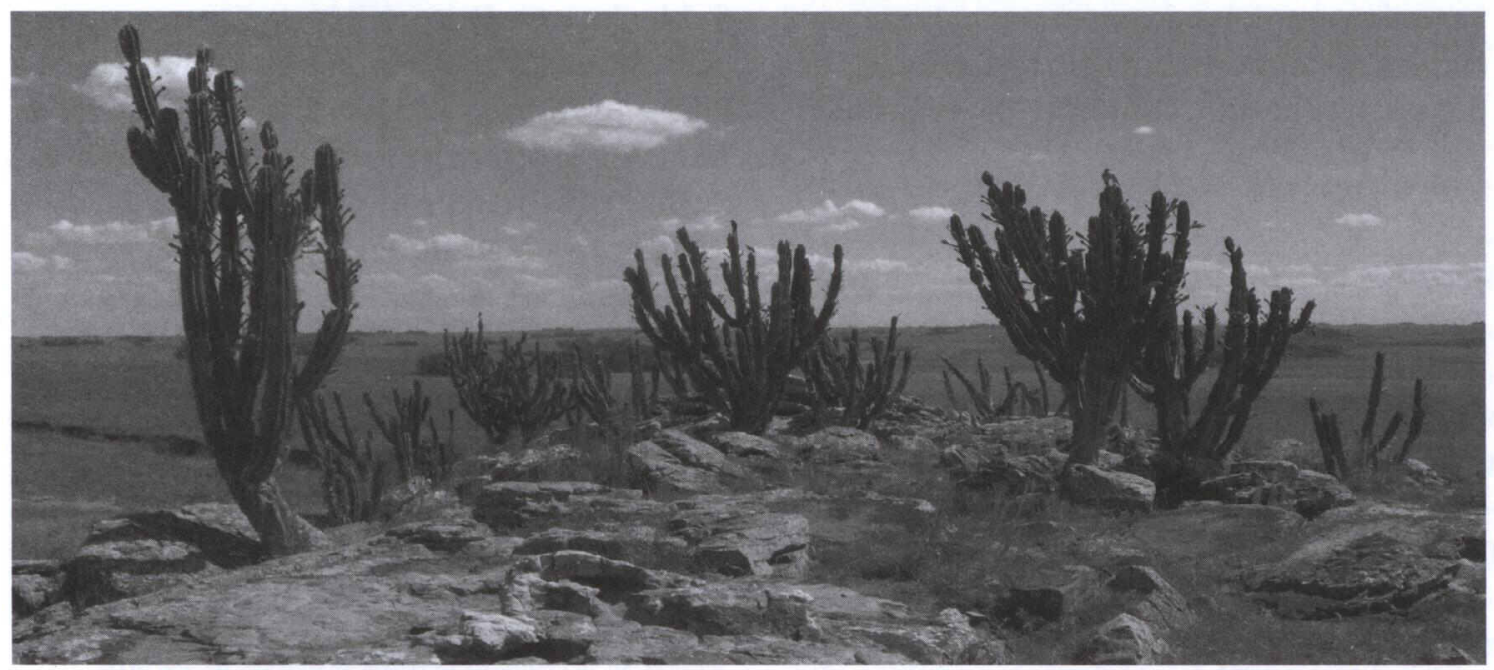

FIGURA 4 - Indivíduos de Cereus hildmannianus K. Schum., em pequena cornija de arenito próxima ao "Cerro das Tunas". 


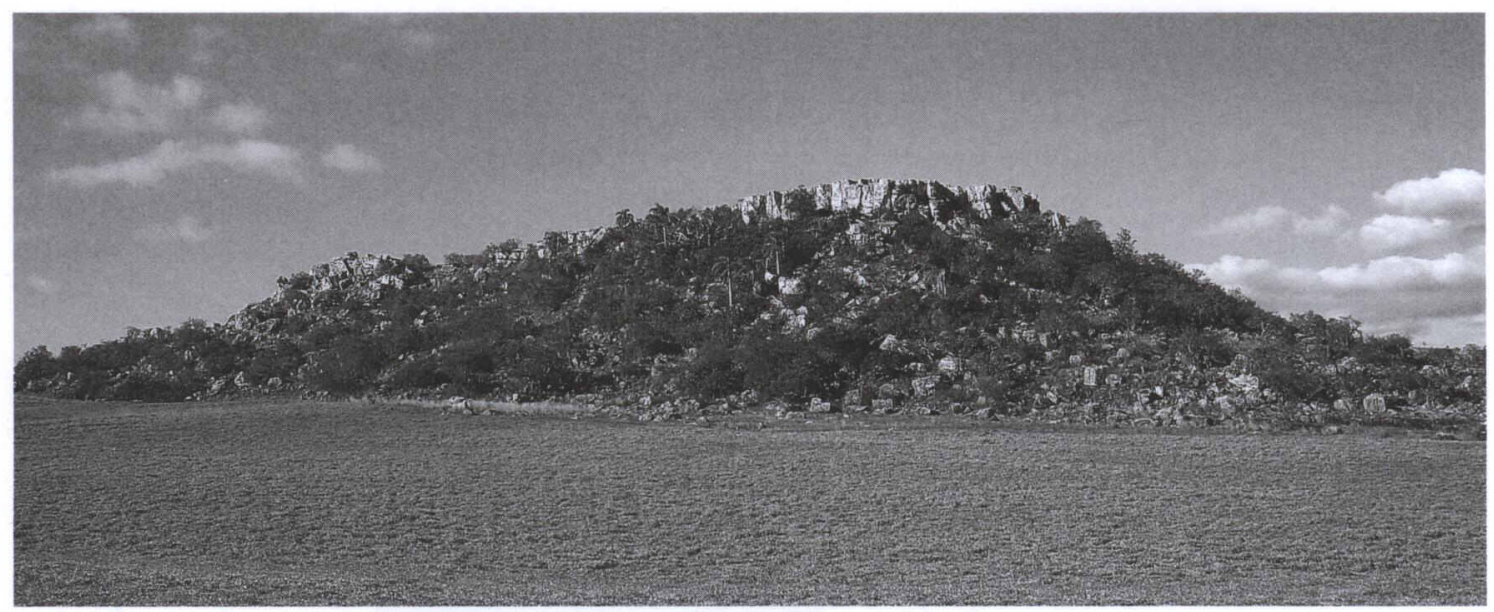

FIGURA 5 - Vista geral do "Cerro da Cascavel", típico morrote de arenito.

\section{2 - Vegetação dos Morrotes de arenito}

Esta tipologia reúne um conjunto de nanofanerófitas e microfanerófitas ${ }^{6}$ xerófilas $^{7}$, em grande parte de espécies endêmicas, bem como suculentas ${ }^{8}$. Conjunto florístico semelhante ao das cornijas, a vegetação de morrotes de arenito reúne diversas ervas e arbustos, como o butiá-anão (Butia lallemantii Deble \& Marchiori) e as Asteráceas Baccharis pampeana An. S. de Oliveira, Deble \& Marchiori e Achyrochline marchiorii Deble.

Nesta unidade, a distribuição da cobertura vegetal ocorre de modo muito particular. O topo, embora geralmente com solo raso e rochas expostas, reúne um conjunto de gramíneas,

6 Microphanerophyta: grupo das fanerófitas que incluem arbustos e árvores pequenas, que conservam gemas foliares entre 2 e 8 metros de altura na estação de repouso vegetativo. (Marchiori, 2006, p. 8).

7 Neste caso, refere-se a plantas adaptadas a ambientes com escassa umidade (xerófitas).

8 Succulentia: categoria de fanerófitas, representada por plantas arbustivas ou arbóreas, geralmente com caules áfilos, suculentos e escassamente lignificados (Marchiori, 2006, p. 8). Plantas com folhas ou caules grossos e carnosos, adaptados ao armazenamento de água. A maior parte das suculentas são xerófitas, plantas que preferem climas secos, como os cactos (ART, 1998 , p. 410). bromeliáceas, cactáceas e até pequenos arbustos. Com aspecto fisionômico diferenciado, a vegetação da encosta apresenta, além de gramíneas, cactos e bromélias, um conjunto de arbustos, arvoretas e árvores dispostas no entorno do morrote, compondo um círculo de vegetação arbustivo-arbórea (Figura 5).

Na encosta dos morrotes, na região do tálus ${ }^{9}$, crescendo entre blocos de rochas, de modo a formar um anel periférico de vegetação, salientam-se, sob o ponto de vista físionômico: a criúva (Agarista eucalyptoides (Cham. \& Schlecht.) G. Don) (Figura 6), o jasmimcatavento (Tabernaemontana catharinensis DC.), o curupi (Sapium haematospermum Müll.Arg.), a tuna (Cereus hildmannianus K. Schum.), o tarumã-preto (Vitex megapotamica (Spreng.) Moldenke), a figueira-do-mato (Ficus luschnathiana (Miq.) Miq.), a pixirica (Miconia hyemalis A. St.-Hil. \& Naudin), o chá-de-bugre (Casearia sylvestris Sw.), o aguaí-vermelho (Chrysophyllum marginatum (Hook. \& Arn.) Radlk.), as guavirovas-do-campo (Campo-

\footnotetext{
9 Superfície inclinada de terreno, na base de um morro, onde se acumulam detritos oriundos da escarpa. Este material, em geral é transportado pelo efeito da gravidade, formando um depósito de talude (Guerra, 1993).
} 


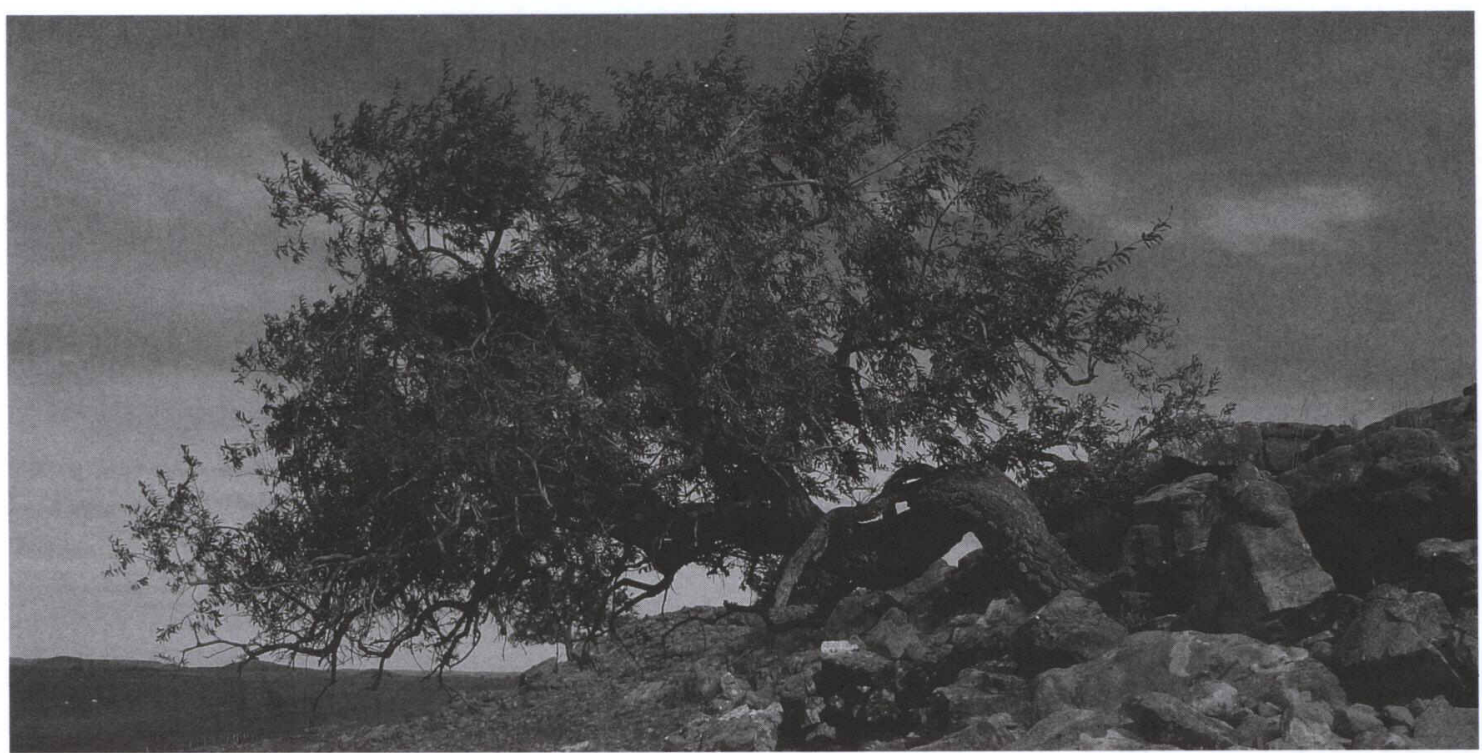

FIGURA 6 - Exemplar de criúva (Agarista eucalyptoides (Cham. \& Schlecht.) G. Don), espécie característica das cornijas e morrotes de arenito.

manesia aurea Berg, Campomanesia hatschbachii Mattos), as pitangas-do-campo (Eugenia arenosa Mattos, Eugenia pitanga (Berg) Niedenzu), os araçás-do-campo (Psidium incanum (Berg) Burret, Psidium luridum (Sprengel) Burret), o pessegueiro-do-campo (Hexachlamys humilis O. Berg), o fumo-bravo (Solanum mauritianum Scop.) e a japecanga (Smilax campestris Griseb.)

Com significativa frequência, encontram-se ainda: o butiá-anão (Butia lallemantii Deble \& Marchiori), o coqueiro-gerivá (Syagrus romanzoffiana (Cham.) Glassman), a murta (Blepharocalyx salicifolius (Kunth) O.Berg), a aroeira-brava (Lithraea molleoides (Vell.) Engl.), o pinheiro-bravo (Podocarpus lambertii Klotsch ex Endl.), a caúna (Ilex dumosa Reissek), o camboatá-vermelho (Cupania vernalis Cambess.), o pessegueiro-bravo (Prunus myrtifolia (L.) Urb.), o coentrilho (Zanthoxylum fagara (L.) Sarg.), a mamica-de-cadela (Zanthoxylum rhoifolium Lam.), o guamirim (Myrceugenia glaucescens (Cambess.) D. Legrand \& Kausel), o chal-chal (Allophylus edulis (A. St.Hil., Cambess.\& A. Juss.) Radlk.), o cocão
(Erythroxylum microphyllum A St.-Hil.) e os garupás (Aloysia gratissima (Hook.) Tronc., Aloysia chamaedryfolia Cham.).

Nos topos de morrotes, salientam-se espécies de menor porte, notadamente de Amarantáceas (Froelichia tomentosa (Mart.) Moq., Pfaffia tuberosa (Spreng.) Hicken), Asclepiadáceas (Oxypetalum campestre Dcne., Oxypetalum erectum Mart. \& Zucc.), Asteráceas (Achyrocline marchiorii Deble, Baccharis pampeana An. S. de Oliveira, Deble \& Marchiori, Baccharis riograndensis Malag. \& J. E. Vidal, Gochnatia cordata Lessing, Lessingianthus macrocephalus (Less.) H. Rob., Porophyllum lineare DC., Tagetes ostenii Hicken, Vernonia brevifolia Lessing), Euforbiáceas (Bernardia multicaulis Müll. Arg., Jathropha isabellei Müll. Arg., Jatropha pedersenii Lourteig, Sebastiana serrulata (Mart.) Müll. Arg.), Leguminosas (Mimosa cruenta Benth., Chamaecrista flexuosa (L.) Greene), além de Macrosiphonia petraea (St.Hil.) K. Schumann (Apocynaceae), Prunus subcoriacea (Chod. et Hassl.) Koehne (Rosaceae), Galium megapotamicum Spreng. 
(Rubiaceae), Scoparia plebeja Cham. et Schlecht. (Scrophulariaceae), Petunia axillaris (Lam.) Britt. (Solanaceae), Waltheria communis St.-Hil. (Sterculiaceae), Hypericum connatum Lamarck (Hypericaceae), Mentha $s p$. (Lamiaceae), Echinocactus muricatus K. Schum. (Cactaceae) e Tillandsia lorentziana Gris. (Bromeliaceae).

\section{CONSIDERAÇÕES FINAIS}

A vegetação das cornijas e morrotes de arenito, apesar da área relativamente pequena ocupada na bacia (cerca de $2 \%$ ), constituem importantes ecossistemas na região. Como áreas de refúgio para a vegetação silvática, abrigam grande diversidade florística, bem como espécies raras ou endêmicas no oeste sul-riograndense.

Isto posto, espera-se que o presente estudo venha a contribuir para o avanço do conheci- mento fitogeográfico sul-rio-grandense e alertar sobre a necessidade de conservação e preservação da biodiversidade e das paisagens naturais no Estado.

\section{REFERÊNCIAS BIBLIOGRÁFICAS}

ALVES, F. da S.; ROBAINA, L.E. de S.; MARCHIORI, J.N.C. Aspectos fitogeográficos da bacia hidrográfica do Arroio Lajeado Grande, RS - Brasil. 1 - O meio físico. Balduinia, Santa Maria, n.18, p. 1-9, 2009.

ART, H. W. Dicionário de Ecologia e Ciência Ambiental. São Paulo: Companhia Melhoramentos, $1998.583 \mathrm{p}$.

GUERRA, A. T. Dicionário geológico-geomorfológico. 8. ed. Rio de Janeiro: IBGE, 1993. $334 \mathrm{p}$.

MARCHIORI, J. N. C. Fitogeografia do Rio Grande do Sul: embasamento florístico. Porto Alegre: EST, 2006. 39 p.

PASSOS, M. M. Biogeografia e paisagem. Maringá: [s.n], 2003. 264 p. 